\title{
Fatigue and Fracture Behavior of Induction-Hardened and Superimposed Mechanically Post-treated Steel Surface Layers
}

\author{
Martin Leitner (D), Florian Grün, Zafer Tuncali, and Wei Chen
}

(Submitted October 25, 2017; in revised form May 1, 2018; published online August 2, 2018)

\begin{abstract}
This paper focuses on the effect of induction hardening and superimposed stroke peening, as mechanical post-treatment, on the fatigue and fracture behavior of gas engine 50CrMo4 steel crankshafts. Comprehensive analysis in regard to local microstructure, hardness and residual stress profile in depth is performed to examine the local characteristics of the investigated crankshafts and the representative notched round specimens. An evaluation of the equivalent von Mises residual stress condition in depth demonstrates an increase by over $70 \%$ of the average compressive residual stress state due to the superimposed stroke peening compared to the induction-hardened condition. Rotating bending fatigue tests reveal that the additional stroke-peening process elevates the high-cycle fatigue strength of the induction-hardened surface layer by $\mathbf{2 0 \%}$, which validates the beneficial effect of the enhanced compressive residual stress state. An extensive fracture surface analysis presents the position of crack initiation for each investigated manufacturing condition indicating that the failure origin preferably starts at the surface for higher load levels. On the contrary, the crack initiation shifts beneath the hardened layer in case of lower load levels leading to subsurface failure origin.
\end{abstract}

Keywords fatigue strength, fracture behavior, induction hardening, residual stress, stroke peening

\section{Introduction}

This paper investigates the effect of thermo-mechanical and superimposed mechanical post-treatment on the fatigue strength enhancement of forged and electroslag remelted large 50CrMo4 steel crankshafts. Focus of the application is laid on stationary gas engines exhibiting a comparably high level of electrical and thermal efficiency (Ref 1). By the permanent increasing demand to optimize specific power output, an enhancement of the local fatigue strength at the highly stressed regions of crankshafts, such as the notched region at the lubrication hole (Ref 2) and the fillets between the web and the crankpin or main journals (Ref 3 ), is therefore of utmost importance. In this work, focus is laid on the latter failure type as fatigue-critical notch case for large crankshafts (Ref 4). A classifier to estimate the failure risk level of a 16-cylinder generator crankshaft based on a dynamic diagnosis and crack growth model is introduced in Ref 5 concluding that the presented procedure is well capable for crack identification. In general, fatigue strength assessment of crankshafts is primarily performed utilizing components testing, which is common for comparable smallscale crankshafts in automotive industry (Ref 6), or by facilitating multiaxial fatigue approaches (Ref 7-9) based on numerical analysis including dynamic load and stress compu-

Martin Leitner and Florian Grün, Chair of Mechanical Engineering, Montanuniversität Leoben, Leoben, Austria; and Zafer Tuncali, GE Jenbacher GmbH \& Co OG, Jenbach, Austria; and and Wei Chen, GE Water \& Distributed Power, Houston, TX. Contact e-mail: martin.leitner@unileoben.ac.at.

\begin{tabular}{|ll|}
\hline \multicolumn{1}{|c|}{ List of symbols } \\
\hline $\mathrm{BM}$ & Base material condition \\
$\mathrm{ESR}$ & Electroslag remelting \\
$\mathrm{IH}$ & Induction-hardened condition \\
$\mathrm{IH}+\mathrm{StrP}$ & Induction-hardened and stroke-peened condition \\
$k$ & Slope of $S / N$ curve in finite life region \\
$N$ & Number of load-cycles to failure \\
$N_{\mathrm{T}}$ & Number of load-cycles at transition knee point \\
$P_{\mathrm{S}}$ & Survival probability \\
$R$ & Load stress ratio \\
$T_{\sigma}$ & Stress-based scatter index \\
$\alpha$ & Angle of the principal stress \\
$\sigma$ & Normal stress \\
$\sigma_{\mathrm{a}}$ & Fatigue stress amplitude \\
$\sigma_{\mathrm{a}, \mathrm{N}=5 \mathrm{e} 6}$ & High-cycle fatigue strength amplitude at \\
& $N=5 \times 10^{6}$ load-cycles \\
$\sigma_{\mathrm{v}}$ & Equivalent von Mises stress \\
$\sigma_{1,2}$ & Maximum/minimum principal stress \\
$\tau$ & Shear stress \\
\hline
\end{tabular}

tation (Ref 10). One common and industrially applied thermomechanical technique to improve the fatigue strength of crankshafts of all sizes is surface induction hardening (Ref 11).

Thereby, numerous process parameters affect the beneficial compressive residual stress condition in the surface layer after the heat treatment, such as power, current frequency and process time during inductive heating as well as the subsequent cooling behavior. An experimental analysis of these process parameters influencing the final residual stress state based on comprehensive $\mathrm{x}$-ray measurements is provided in Ref 12 . Besides heat treatment processes, also mechanical post-treatment methods like deep rolling are applied especially at the fillets of crankshafts (Ref 13). Again, the fatigue strength 
enhancing effect results from a compressive residual stress condition within the surface layer. Nowadays, nonlinear numerical simulation techniques are commonly employed to optimize process parameters in regard to durability (Ref 14). Another mechanical post-treatment is stroke peening, respectively, machine hammer peening (Ref 15 ). On the contrary to deep rolling, this technique is a highly dynamic peening process leading to comparably increased impact forces and therefore, to a rather enhanced compressive residual stress state within the post-treated surface layer. Typically, these introduced post-treatment processes are individually applied depending on the industrial technical and economical effort. A superimposed application of a thermo-mechanical and mechanical process is quite rare. However, a study in Ref 16 investigating the effect of shot peening on laser-hardened surfaces reveals a major increase in fatigue life due to the superimposed mechanical treatment.

Hence, this work scientifically contributes to evaluate the effect of superimposed mechanical stroke peening on the local material properties and high-cycle fatigue strength (Ref 17) of induction-hardened notched surface layers. Figure 1 depicts a schematic representation of the manufacturing procedure as well as the analyzed local characteristics, such as hardness and compressive residual stress distribution in depth, at the loaddependent highly stressed region of the notch root.

\section{Specimen Design and Manufacturing}

\subsection{Geometry and Extraction Position}

Based on a preliminary study incorporating a dynamic load and stress analysis of a 16-cylinder gas engine crankshaft, local stress distributions at the highly stressed fillets between the web and the crankpin as well as main journals is numerically evaluated (Ref 18). Subsequently, a notched round specimen exhibiting a testing diameter of $d=30 \mathrm{~mm}$ is designed, which features a comparable local stress distribution in depth by applying an external four-point bending load in the course of the experiments; see Fig. 2.

Therefore, specimen fatigue test results, which are transferable to the real gas engine crankshaft application in terms of the local load-induced stress distribution, are ensured.

As the crankshafts are forged components, the specimens are directly extracted from the ends of the crankshafts; see

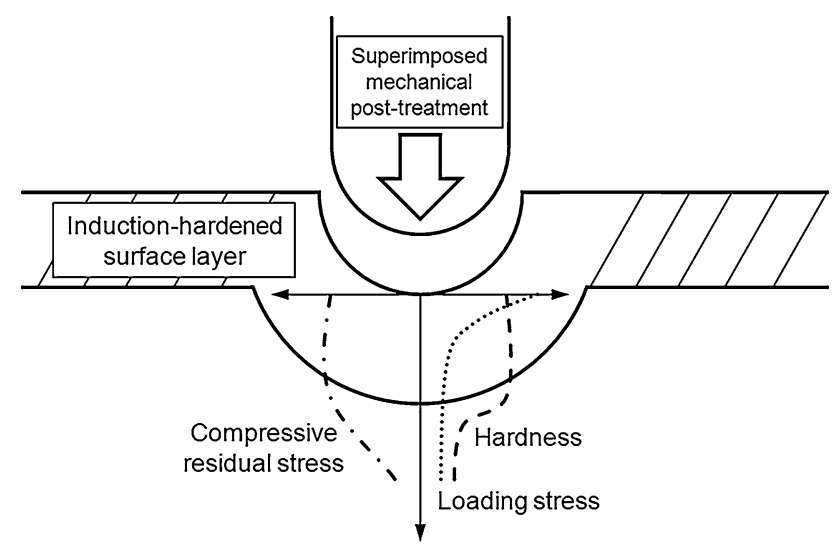

Fig. 1 Schematic representation of manufacturing procedure
Fig. 3. With reference to the crankshaft, this extraction procedure guarantees a similar microstructure and material behavior as the base material condition for the specimens.

\subsection{Base Material}

In the frame of this study, 50CrMo4 steel crankshafts in forged and electroslag remelted (ESR) condition are utilized as base material. Preliminary work investigating the uni- and multiaxial fatigue strength of this material is presented in Ref 19. It is shown that the ESR process has a remarkable influence on the tension/compression high-cycle fatigue strength at a stress ratio of $\mathrm{R}=-1$ with an increase of about $37 \%$ compared to the condition before ESR. The nominal chemical composition of the 50CrMo4 steel as base material is specified as 0.46 to $0.54 \% \mathrm{C}$, maximum $0.40 \% \mathrm{Si}, 0.50$ to $0.80 \% \mathrm{Mn}$, 0.90 to $1.20 \% \mathrm{Cr}$, and 0.15 to $0.30 \%$ Mo by mass according to Ref 20.

The nominal mechanical properties of 50CrMo4 round bars for diameters between 16 and $40 \mathrm{~mm}$, which fit to the size of the utilized specimen geometry, are provided in Table 1. The data can be considered as minimum values, which apply for the used base material and specimen size.

Utilizing the designed specimen geometry, both posttreatment procedures are applied in order to achieve comparable local material conditions as of the real crankshafts. To validate the material properties, metallographic inspections as well as Vicker's hardness and x-ray residual stress measurements in depth are performed, which are subsequently presented in detail.

\subsection{Induction Hardening and Stroke Peening}

After extracting and final machining of the specimens, twothird of the specimen lot is subsequently heat-treated by surface induction hardening. Relevant process parameters within the inductive heating and water cooling process are adopted in order to achieve a comparable microstructure in the surface layer as well as similar hardness and residual stress profiles in depth.

The induction hardening process of the specimens is performed utilizing inductors, which move along the axial axis of the samples and which are consisting of two separate encircling round coils with different frequencies of the electromagnetic field. The first coil possesses a medium frequency to achieve global heating, and the second coil features a high frequency to intensify local heating within the surface layer of the specimen. The subsequent quenching process is done by spray cooling process, in which again an encircling round nozzle is moving along the axial axis of the specimens. A detailed description of the manufacturing process including a representation of a numerical process simulation of the induction hardening illustrating the heat flow during heating and cooling is provided in Ref 21 .

Figure 4 shows a micrograph in etched condition of an induction-hardened surface layer of a crankshaft fillet exhibiting a heat-treated depth of about $3 \mathrm{~mm}$ at the highly stressed point. Additionally, the fine-grained martensitic microstructure in the surface layer evaluated by light-optical microscopy is illustrated.

After experimentally optimizing the induction hardening process parameters for the manufacturing of the specimens, the final heat treatment depth reveals an almost identical value of about $3 \mathrm{~mm}$ compared to the crankshaft. Additionally, the mean 


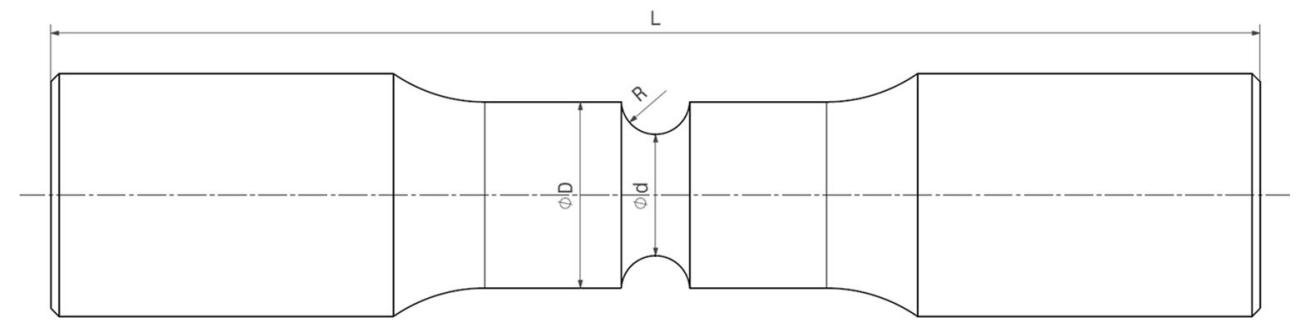

Fig. 2 Geometry of investigated notched round specimen
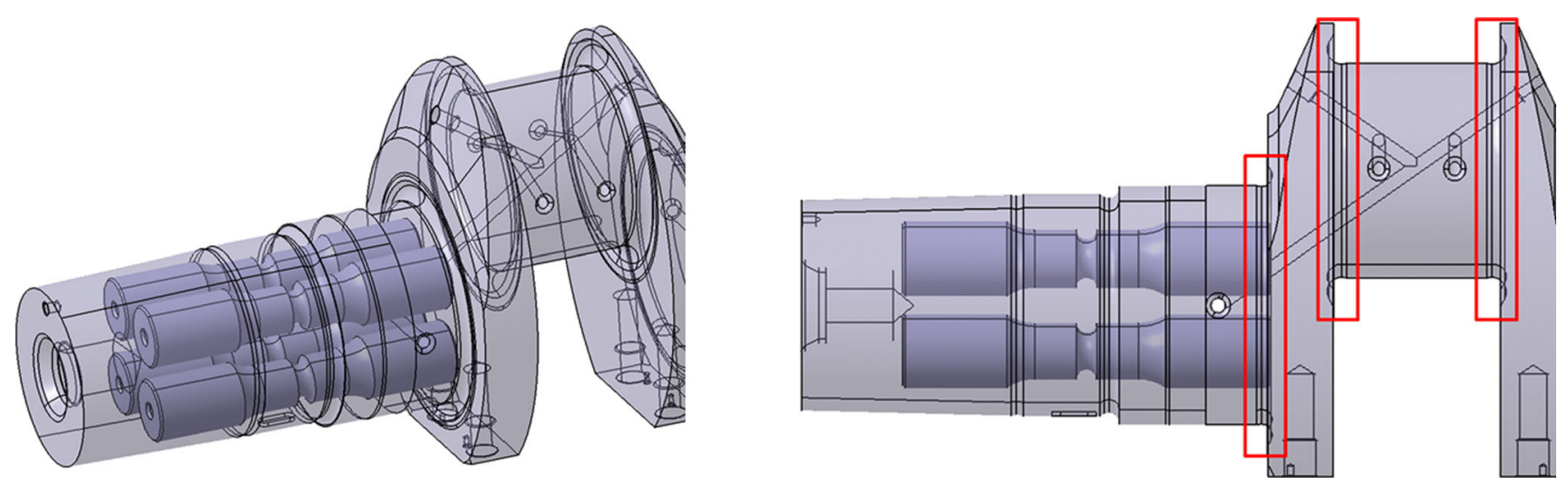

Fig. 3 Extraction position of specimens at the end of the crankshaft and representation of the highly stressed fillets (see labeling)

Table 1 Mechanical properties of base material (Ref 19)

\begin{tabular}{lccc}
\hline Yield strength, MPa & Ultimate strength, MPa & Elongation at rupture, \% & Reduction of area, \% \\
\hline 780 & $1000-1200$ & 10 & 45 \\
\hline
\end{tabular}

Vicker's hardness in the surface layer indicates just a minor deviation of approximately $5 \%$ between the specimen and crankshaft. However, as the heating and cooling conditions are geometry-dependent fundamentally different between both geometries, this specimen condition is taken as well optimized basis for the further analysis.

Subsequently, half of the induction-hardened specimens, equaling one-third of the specimen lot, are additionally posttreated by stroke peening. The mechanical process is shown in Fig. 5 representing a hardened pin exhibiting a tip radius comparable to the notch radius, which iteratively impacts the surface at the notched area of the specimen. Again, an experimental process parameter pilot study, incorporating the applied impact force and distance between two strokes, is performed in order to obtain a comparable hardness and residual stress profile in depth matching to the crankshaft. Microscopic analysis reveals that due to the superimposed mechanical treatment no significant change of the martensitic microstructure within the hardened surface layer occurs. This is also in accordance to the hardness measurement results, whereby no distinctive modification after applying the strokepeening process is detectable. Final mean hardness values of the specimens are again in sound agreement to the values of the crankshaft with a minor difference of about $1 \%$.

Summarized, microstructure and hardness condition of the specimens agree well to the behavior of the real crankshaft, which enables the experimental investigation utilizing the introduced representative round specimens. The final Vicker's hardness measurement profiles in depth, normalized by the average value of the base material, are depicted in Fig. 6 for the investigated testing conditions. Firstly, it is observed that the induction hardening $(\mathrm{IH})$ process significantly increases the local hardness in the surface layer by a factor of about two compared to the base material (BM) behavior. Secondly, the superimposed stroke-peening condition $(\mathrm{IH}+\mathrm{StrP})$ leads to a minor reduction in the hardness state by about $5 \%$ and to a slight enhancement of the hardening depth by about $0.5 \mathrm{~mm}$ on average. These two effects can be mostly drawn to a softening of the induction-hardened structure in the surface layer and to a hardening of material beneath the induction-hardened zone.

In Ref 22 hardened steel specimens are additionally deeprolled, where it is concluded that the values of microhardness tend to decrease with the elevation of number of passes. In the course of the StrP process, the pin hits one position several times due to the overlapping, which can be equated by a multiple number of passes for deep rolling. Hence, the observed softening is also shown within other investigations substantiating the findings in this work.

\section{Residual Stress Conditions}

In addition to the analysis of the local microstructure and hardness state, comprehensive residual stress measurements based on the X-ray diffraction method (Ref 23) are performed at 

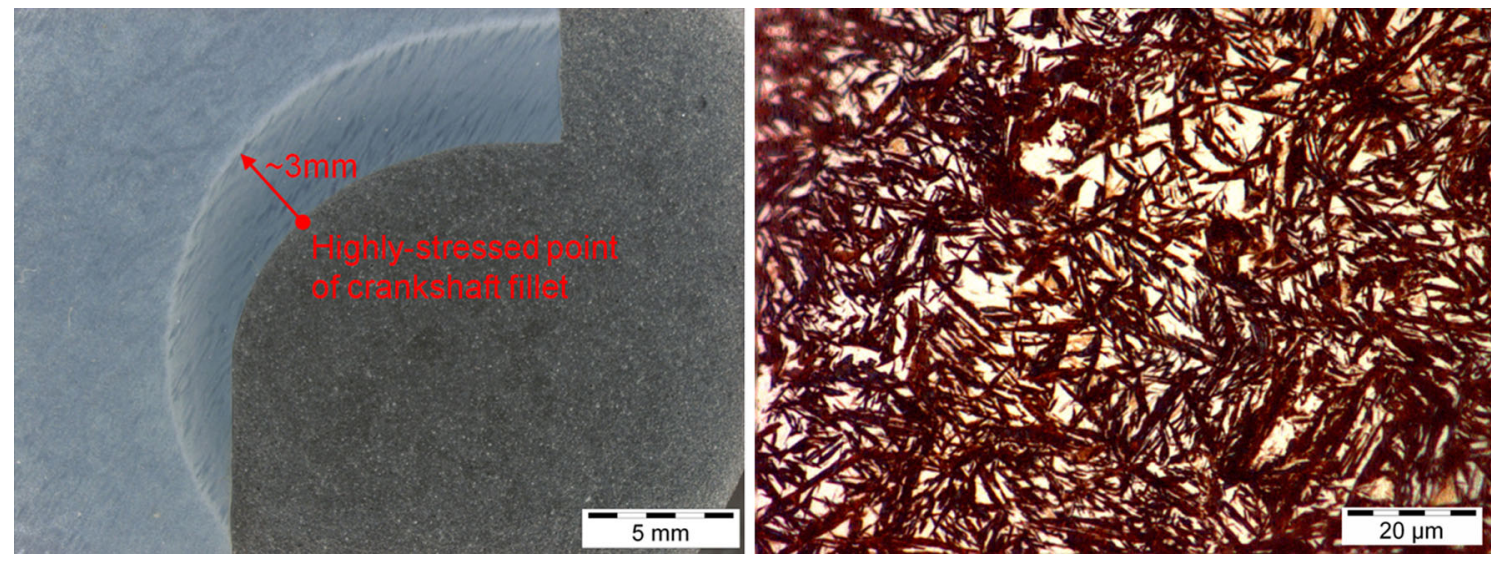

Fig. 4 Induction hardening depth at fillet of crankshaft (left) and microstructure in surface-hardened layer (right)

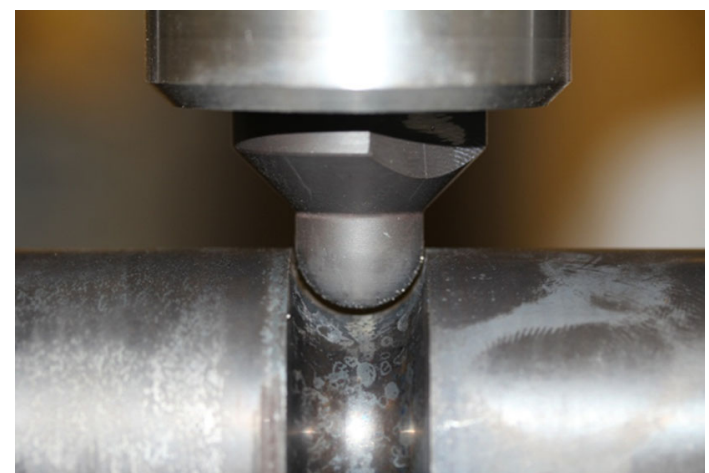

Fig. 5 Stroke peening of induction-hardened specimen

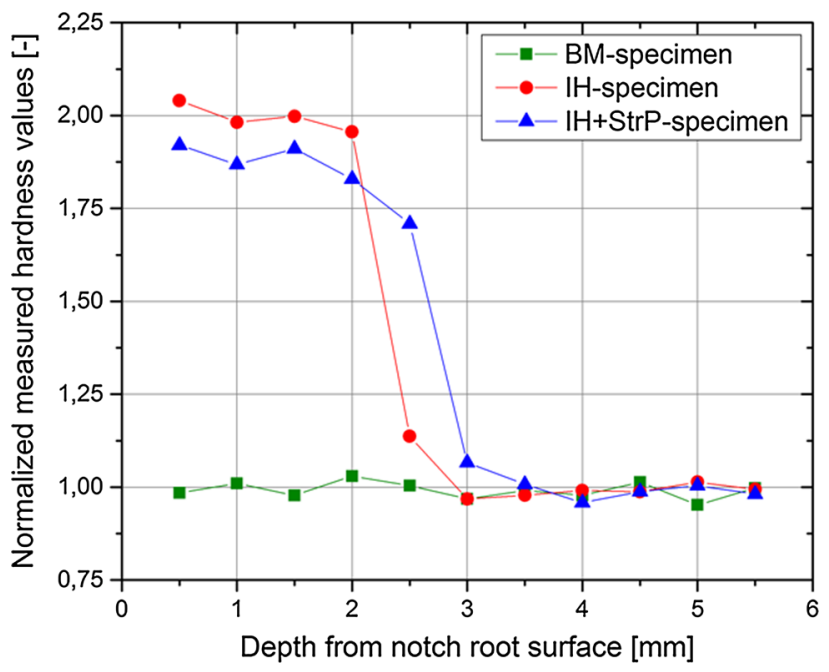

Fig. 6 Comparison of normalized hardness profiles in depth

the notch area in order to validate whether a similar residual stress condition of the specimens compared to the crankshaft is accomplished. Due to major differences in global size, geometry in the adjacent area of the notch, and manufacturing process parameters, no complete conformity may be achieved; however, a matchable quantitative distribution acts as fundament to obtain equivalent and transferable results within the fatigue tests. Herein, the residual stresses are evaluated utilizing $\mathrm{CrK} \alpha$ radiation by applying the $d(\sin 2 \Psi)$ cross-correlation method with a collimator size of $1 \mathrm{~mm}$, and a duration of exposure of $30 \mathrm{~s}$. The presented residual stress distributions are normalized using a mean value of the base material's yield strength evaluated in the course of several quasi-static tensile tests.

Figure 7 depicts the residual stress state in axial direction, which is the loading direction within the subsequently performed four-point bending fatigue tests, for the specimen in induction-hardened condition. For validation, the corresponding residual stress distribution of the crankshaft measured at a highly stressed fillet as pictured in Fig. 3 is presented. It is shown that the mean values at the surface-near layer up to a depth of $50 \mu \mathrm{m}$ agree well with a difference of just $5 \%$. Further on, it is observable that the specimen features a slightly increased compressive residual stress state up to the final measurement depth of $1500 \mu \mathrm{m}$ compared to the results of the crankshaft. Nevertheless, a generally sound accordance between the specimen and the crankshaft is still attained.

The residual stress measurement results in tangential direction, which equals the circumference direction at the surface of the notch, for the specimen and crankshaft in induction-hardened condition are provided in Fig. 8. In this case, again the residual stress values at the near surface region up to $50 \mu \mathrm{m}$ agree well exhibiting a difference of up to $10 \%$. On the contrary to the measurement results in axial direction, the tangential stress distribution in depth reveals a minor increased compressive residual stress state for the crankshaft compared to the specimen. This behavior may be explained by a significant different heat flow and cooling behavior in the course of the heat treatment due to the different sizes of both analyzed geometries. Especially in tangential direction, an enhanced heat flow is enabled by the huge crankshaft diameter equalling about a factor of five compared to the specimen in this area, which leads to superior cooling rates and therefore, a higher compressive residual stress state. However, generally both residual stress distributions match quite well especially near the surface, which again facilitates a transferability of the specimen fatigue test results to the crankshaft behavior.

Figures 9 and 10 depict the $\mathrm{x}$-ray residual stress measurement results for the specimen and crankshaft in inductionhardened and superimposed stroke-peened condition for the axial and tangential direction. At first, a comparison of the surface near as well as the continuing distribution in depth indicates that the specimen values coincidence well with the measurements for the crankshaft. In case of the surface-near 
layer up to $50 \mu \mathrm{m}$, only minor differences of about $10 \%$ in regard to the measured mean values in axial and tangential direction arise, which proof the applicability of the heat- and mechanical post-treatment parameters for the investigated specimens.

Comparing the further residual stress distribution up to the final measured depth of $1500 \mu \mathrm{m}$, the results in axial direction demonstrate a sound agreement with deviations of up to only $5 \%$. Focussing on the tangential direction, slightly raised distinctions appear, whereby a higher compressive residual stress state for the specimen is observed. Again, these results may be drawn to the different geometrical boundary conditions during the stroke-peening process. Hereby, the local contact stress situation at the notch of the specimen features major differences compared to the crankshaft. This leads to elevated variations of the local plasticized surface zone, especially in tangential direction due to the aforementioned distinctive diameter difference. Hence, a higher compressive residual stress level is enabled in case of the investigated specimen due to comparably enhanced plastification conditions based on the

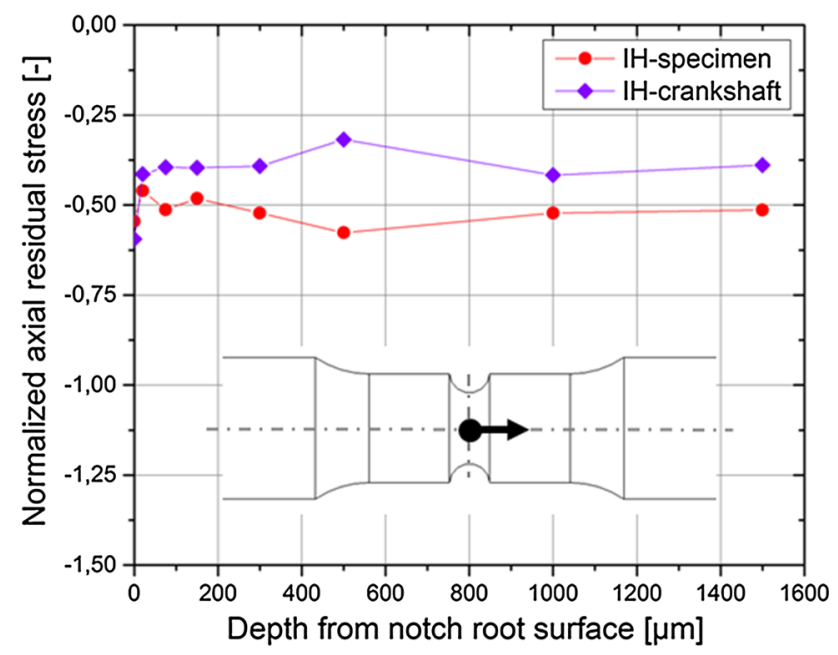

Fig. 7 Residual stress state in axial direction for specimen and crankshaft in induction-hardened condition

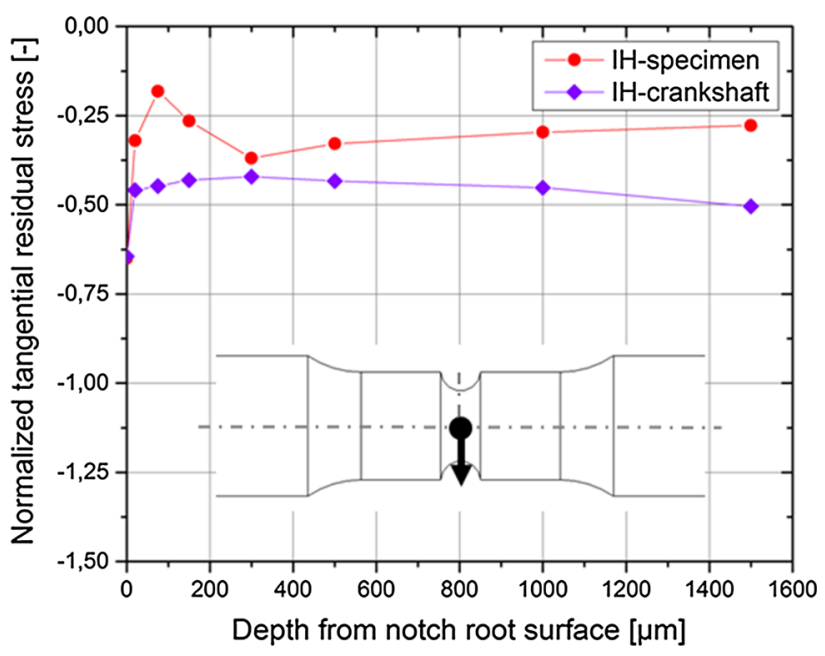

Fig. 8 Residual stress state in tangential direction for specimen and crankshaft in induction-hardened condition decreased geometrical size in relation to the huge gas engine crankshaft.

Summarized, in both post-treatment conditions, namely IH and $\mathrm{IH}+\mathrm{StrP}$, the measured residual stress states agree well in the surface-near layer up to a depth of about $50 \mu \mathrm{m}$. However, different geometrical dimensions and local boundary conditions between the specimen and the crankshaft lead to local processdependent deviations during induction hardening and the superimposed stroke peening. This causes differences in the further evaluated residual stress distribution up to a depth of $1500 \mu \mathrm{m}$. Nevertheless, as these results represent the final state of a preceding process parameter study, a further improvement in regard to achieve more coinciding values is not expected due to the acting size-effects.

In order to investigate a fully defined plain stress residual stress state in depth, additional x-ray measurements at an angle of 45 degrees between the axial and tangential direction are performed in case of the crankshaft, which are defined as $\sigma_{12}$. Based on these three measured stress directions, namely $\sigma_{11}$ for axial, $\sigma_{22}$ for tangential and $\sigma_{12}$ for the stress under 45 degrees, the resulting principal residual stresses $\sigma_{1,2}(\mathrm{Eq} 1)$ as well as the equivalent von Mises residual stress $\sigma_{\mathrm{v}}(\mathrm{Eq} 2)$ is calculated. In addition, Eq 3 is utilized in order to evaluate the angle $\alpha$, under which the principal residual stress state compared to the tangential stress direction occurs.

$\sigma_{1,2}=\frac{\sigma_{11}+\sigma_{22}}{2} \pm \sqrt{\left(\frac{\sigma_{11}-\sigma_{22}}{2}\right)^{2}+\sigma_{12}^{2}}$

$\sigma_{\mathrm{v}}=\sqrt{\sigma_{11}^{2}-\sigma_{11} \sigma_{22}+\sigma_{22}^{2}+3 \sigma_{12}^{2}}$

$\alpha=\frac{1}{2} \tan ^{-1}\left(\frac{2 \sigma_{12}}{\sigma_{11}-\sigma_{22}}\right)$

Figure 11 illustrates the calculated principal residual stress condition for the crankshaft incorporating both post-treatment conditions. Herein, the maximum principal stress $\sigma_{1}$ is similar before and after performing the stroke-peening process with values around zero. Special focus needs to be laid on the minimum principal stress $\sigma_{2}$, which clearly reflects the influence of the superimposed mechanical post-treatment. Based on

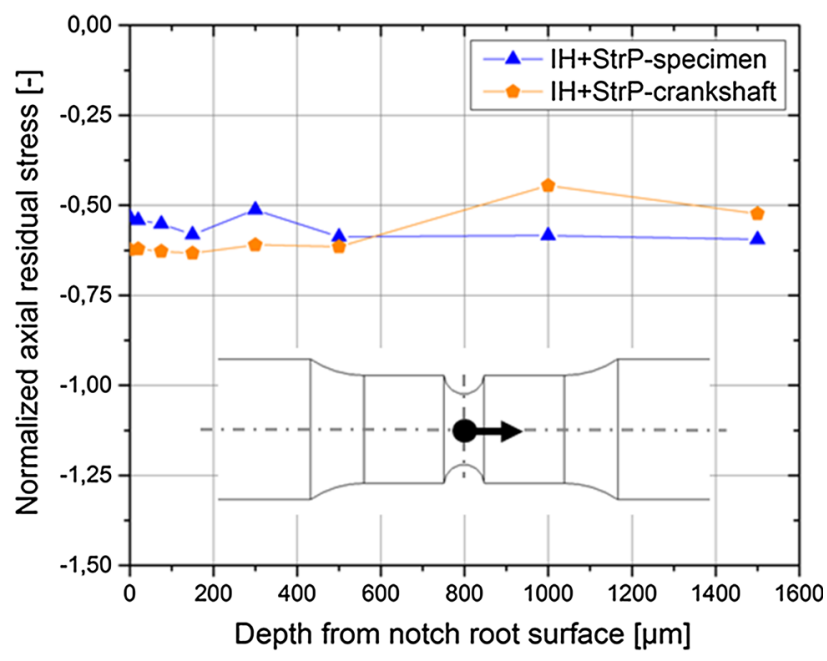

Fig. 9 Residual stress state in axial direction for specimen and crankshaft in induction-hardened and stroke-peened condition 


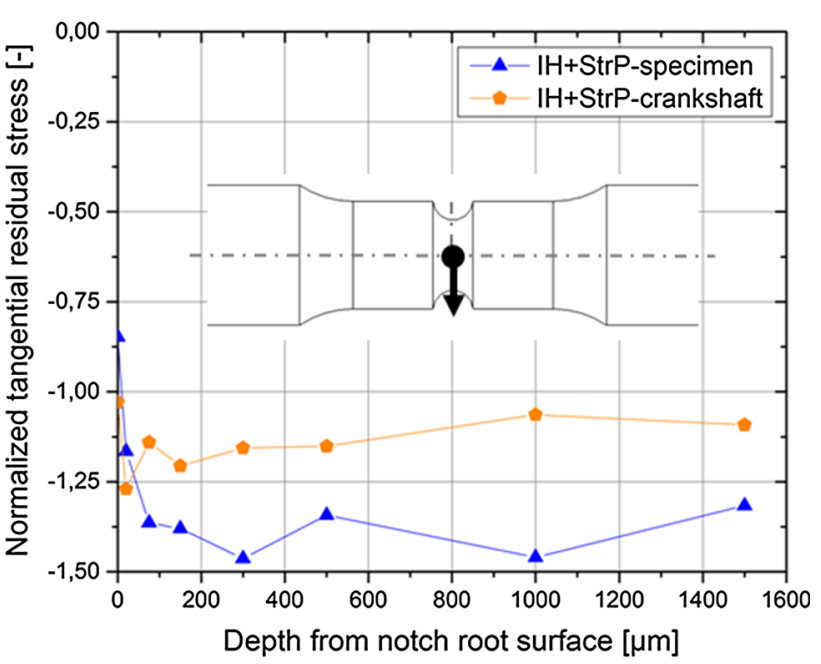

Fig. 10 Residual stress state in tangential direction for specimen and crankshaft in induction-hardened and stroke-peened condition

these results it can be concluded that the stroke peening significantly increases the compressive residual stresses in depth by over $70 \%$ on average. Additionally, the absolute value of the angle of the principal stress $\alpha$ changes from about $43^{\circ}$ in case of $\mathrm{IH}$ to around $34^{\circ}$ for the $\mathrm{IH}+\mathrm{StrP}$ condition, which reflects that the compressive residual stress direction is slightly shifted toward the tangential stress direction. This behavior can be explained as the increase in compressive residual stresses is higher in case of the tangential compared to the axial direction, as shown in the evaluations before.

Figure 12 presents the computed equivalent von Mises residual stress state for the crankshaft incorporating both posttreatment conditions. The values are depicted as compressive residual stresses exhibiting a negative prefix in order to enhance comparability to the prior results. The evaluated equivalent von Mises residual stress results reveal again a major increase of the compressive residual stress state due to the superimposed stroke-peening process by a mean value of over $70 \%$. Summarized, it is shown that in both post-treatment stages, multiaxial stress conditions in the notch arise, which is in agreement to other studies, e.g., by Ref 12 . The elevation of the compressive residual stress state beneficially contributes to a fatigue strength enhancement, which will be discussed in the subsequent chapter.

\section{Fatigue Tests}

\subsection{Results}

This section focuses on the experimental fatigue strength evaluation of the specimens incorporating the investigated posttreatment conditions. Therefore, the samples are cyclically tested under four-point rotating bending at an alternating stress ratio of $\mathrm{R}=-1$. Run-out level is defined at a number of $5 \times 10^{6}$ load-cycles and the failure criterion is set as burst fracture of the specimen. The resulting fatigue data points are statistically analyzed utilizing the procedure in Ref 24 for the finite life region and the ArcSin $\sqrt{\mathrm{P}}$-transformation to evaluate the high-cycle fatigue resistance $\sigma_{\mathrm{a}, \mathrm{N}=5 \mathrm{e} 6}$ as presented in Ref 25 in order to obtain nominal $S / N$ curves for a survival probability

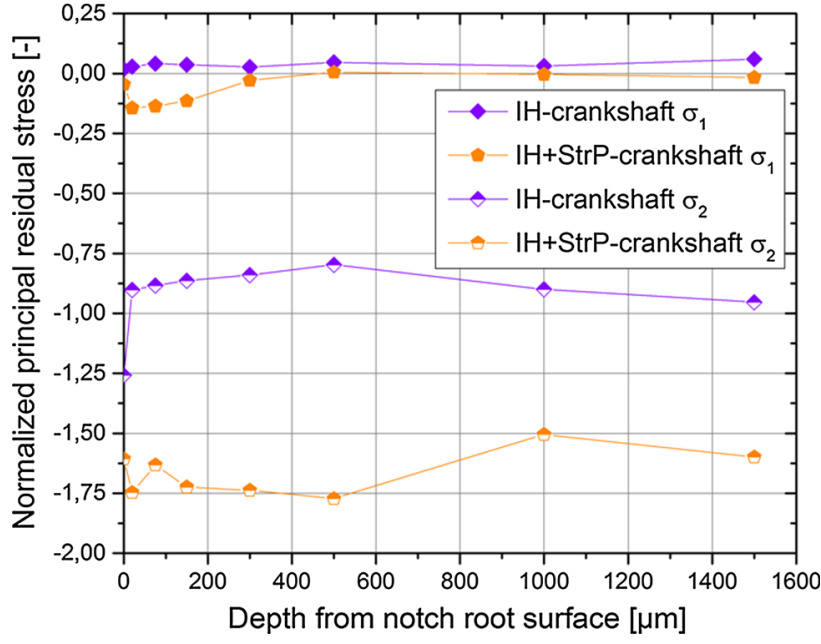

Fig. 11 Principal residual stress state for crankshaft in both posttreatment conditions

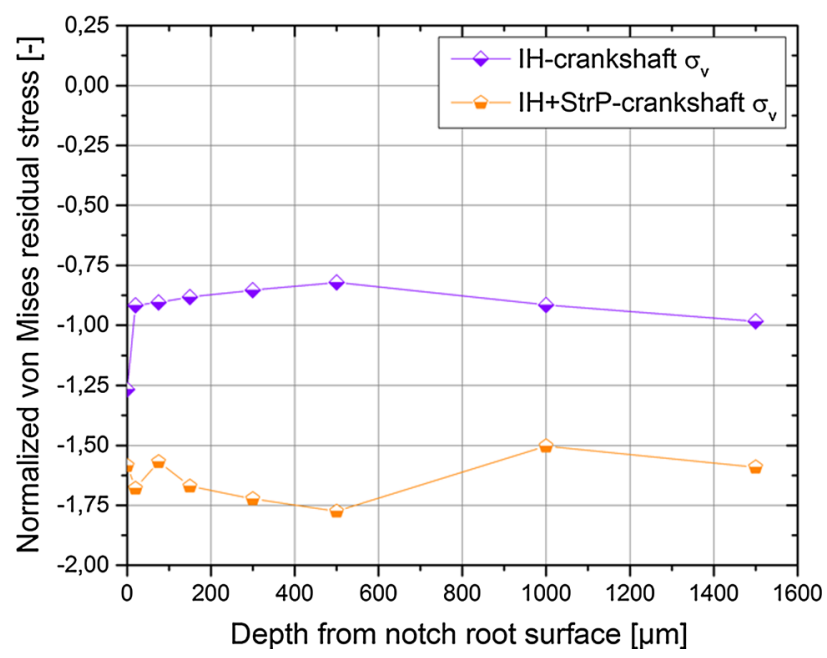

Fig. 12 Equivalent von Mises residual stress state for crankshaft in both post-treatment conditions

of $P_{\mathrm{S}}=50$ and $90 \%$. The resulting fatigue strength results for the base material (BM), induction-hardened (IH), and superimposed stroke-peened $(\mathrm{IH}+\mathrm{StrP})$ condition are compared in Fig. 13. Thereby, all values are normalized with the statistically evaluated high-cycle fatigue resistance of the base material at $5 \times 10^{6}$ load-cycles for $P_{\mathrm{S}}=50 \%$.

Firstly, it is observed that the induction hardening as heat treatment significantly increases the high-cycle fatigue strength by over $45 \%$ compared to the base material behavior, which is in accordance to the suggested surface treatment factor in the range of 1.2 to 2.5 in Ref 26 . The statistically evaluated slope in the finite life region is decreased in case of the heat-treated condition exhibiting a value of $k=9.8$ in relation to $k=15.8$ for the base material. Scattering of the results in the high-cycle fatigue region is quite similar in both manufacturing conditions with a maximum scatter band of $1 / T_{\sigma}=1.10$, which equals the ratio of $\sigma_{\mathrm{a}, \mathrm{N}=5 \mathrm{e} 6}$ at a survival probability of $P_{\mathrm{S}}=10$ to $90 \%$. In addition, the number of load-cycles at the transition knee point reduces from $N_{\mathrm{T}}=1.4 \times 10^{6}$ for the base material to $\mathrm{N}_{\mathrm{T}}=$ $7.9 \times 10^{5}$ for the induction-hardened condition. 
Secondly, the superimposed stroke peening leads to a further distinctive enhancement of $\sigma_{\mathrm{a}, \mathrm{N}=5 \mathrm{e} 6}$ with an increase by $75 \%$ compared to the base material, and by almost $20 \%$ compared to the induction-hardened condition. The evaluated slope in the finite life region exhibits a value of $k=9.7$, which is nearly identical to the induction-hardened one, and the scatter band reveals a minor value of $1 / T_{\sigma}=1.03$. Again, the number of load-cycles at the transition knee point is decreasing to a value of $N_{\mathrm{T}}=2.7 \times 10^{5}$, contributing to the increase of the fatigue strength behavior by the mechanical post-treatment process. A summary of the evaluated $S / N$ curve parameters is provided in Table 2.

\subsection{Fracture Surface Analysis}

As fundamental differences in regard to the position of the crack initiation depending on the specimen type and load level occur, this section provides a comprehensive overview of the fractured surfaces. Figure 14 shows a fracture surface of a base material specimen tested at a normalized stress amplitude of $\sigma_{\mathrm{a}}=1.28$ leading to a number of about $2 \times 10^{4}$ load-cycles until burst fracture.

Microscopical analysis indicates crack initiation at the surface of the notch root around the circumference of the specimen, which is typically for base material specimens tested under rotating bending load. After initiation, the cracks propagate toward the centre of the specimen until the critical stress intensity at the crack tip is reached leading to the burst fractured area in the middle. This failure mode is observed for all base material specimens without evaluating an effect by the applied load level.

A fracture surface of an induction-hardened specimen, tested at a comparably high load level of $\sigma_{\mathrm{a}}=1.85$ leading to a number of about $6.3 \times 10^{4}$ load-cycles until burst fracture, is depicted in Fig. 15. Thereby, again crack initiation at the

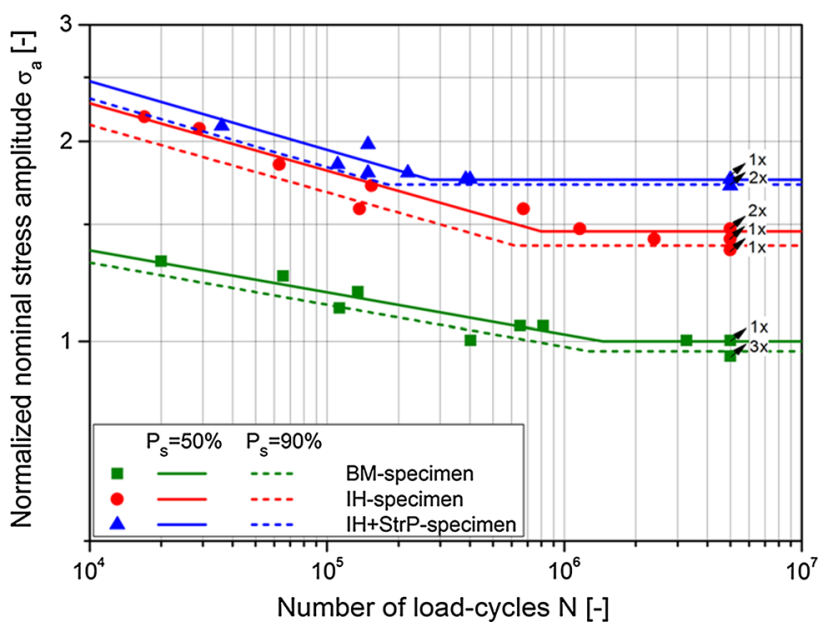

Fig. 13 Normalized nominal stress $S / N$ curves surface of the notch root around the circumference of the specimen is detected. Herein, the crack quite quickly propagates toward to the centre due to the martensitic brittle material behavior in the hardened surface layer, whereby increased crack growth rates generally occur (Ref 27 ).

A more detailed observation of the crack initiation sites in the areas 1, 2, and 3 in Fig. 15 shows that multiple cracks origin at the surface of the notch root. It can be monitored that the cracks in subfigures 2 and 3 are dominating exhibiting a larger crack size in depth compared to the crack in subfigure 1. These findings can be explained by the fact that the local properties in the material, especially within the hardened surface layer, are not completely identical within the highly stressed volume leading to differences in the final crack sizes. However, as the fatigue test results demonstrate a comparably minor scatter band, no major deviations in the local characteristics between the tested specimens occur, which validates a proper manufacturing quality leading to reproducible results.

On the contrary, Fig. 16 presents the fracture surface of an induction-hardened specimen tested at a comparably low load level of $\sigma_{\mathrm{a}}=1.48$ leading to a number of about $1.2 \times 10^{6}$ loadcycles until burst fracture. Microscopical analysis reveals that in this case the crack initiation does not arise at the surface of the notch root, but within the material in the area of the transition from the induction-hardened layer to the core region. In principle, this fracture mode is typical for cyclically-loaded surface-hardened components, which is for example also observed for induction-hardened shafts under shear stress loading in Ref 28. The reason for this phenomenon can be explained based on the concept of the local fatigue strength introduced in Ref 29. Herein, the fatigue resistance distribution in depth is dependent on the local hardness and residual stress profile as well as the external load-induced stress gradient. As usually a high fatigue resistance is achieved within the surfacehardened layer, the local fatigue strength may not be exceeded at the surface, but at a certain depth below the hardened layer. A study in Ref 30 focussing on the application of the local fatigue strength approach for martensitic surface layers shows that especially in case of smoothly notched geometries exhibiting shallow load stress gradients in depth, the local fatigue strength is typically exceeded below the surface leading to subsurface crack initiation.

In addition, a study incorporating a numerical simulation of the induction hardening process and a subsequent local fatigue assessment based on the notch strain approach utilizing the same specimens as in this work is recently published; see Ref 21. Herein, the local manufacturing process-dependent fatigue parameters are estimated on the basis of the numerical results, which reveal major differences between the induction-hardened surface layer and the core region. An application of this methodology proofs that in case of comparably minor load levels near the run-out region, the local fatigue strength is exceeded directly at the transition from the hardened surface layer to the core material, which validates the experimental findings in this work. A detailed analysis of the fractured

Table 2 Summary of $S / N$ curve parameters

\begin{tabular}{lccc}
\hline Condition & Normalized fatigue strength $\boldsymbol{\sigma}_{\mathbf{a}, \mathbf{N}=\mathbf{5 e 6}}$ & Slope $\boldsymbol{k}$ in the finite life region & Number of load-cycles $\boldsymbol{N}_{\mathbf{T}}$ at transition knee point \\
\hline $\mathrm{BM}$ & 1.00 & 15.8 & $1.4 \times 10^{6}$ \\
$\mathrm{IH}$ & 1.46 & 9.8 & $7.9 \times 10^{5}$ \\
$\mathrm{IH}+\mathrm{StrP}$ & 1.75 & 9.7 & $2.7 \times 10^{5}$ \\
\hline
\end{tabular}



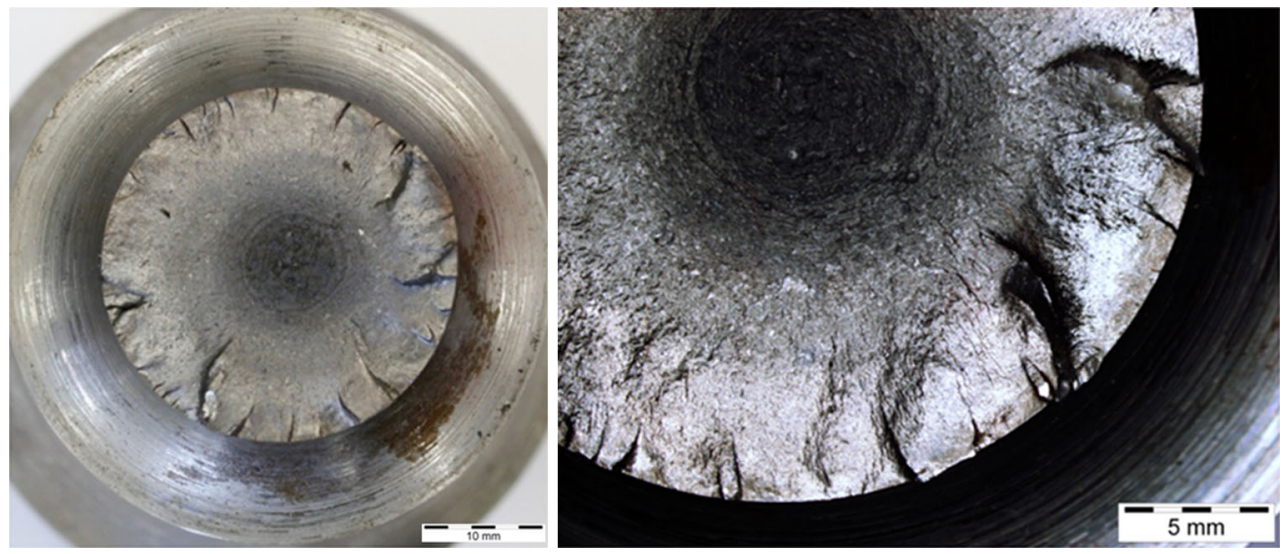

Fig. 14 Fracture surface of base material specimen tested at a normalized stress amplitude of $\sigma_{\mathrm{a}}=1.28$
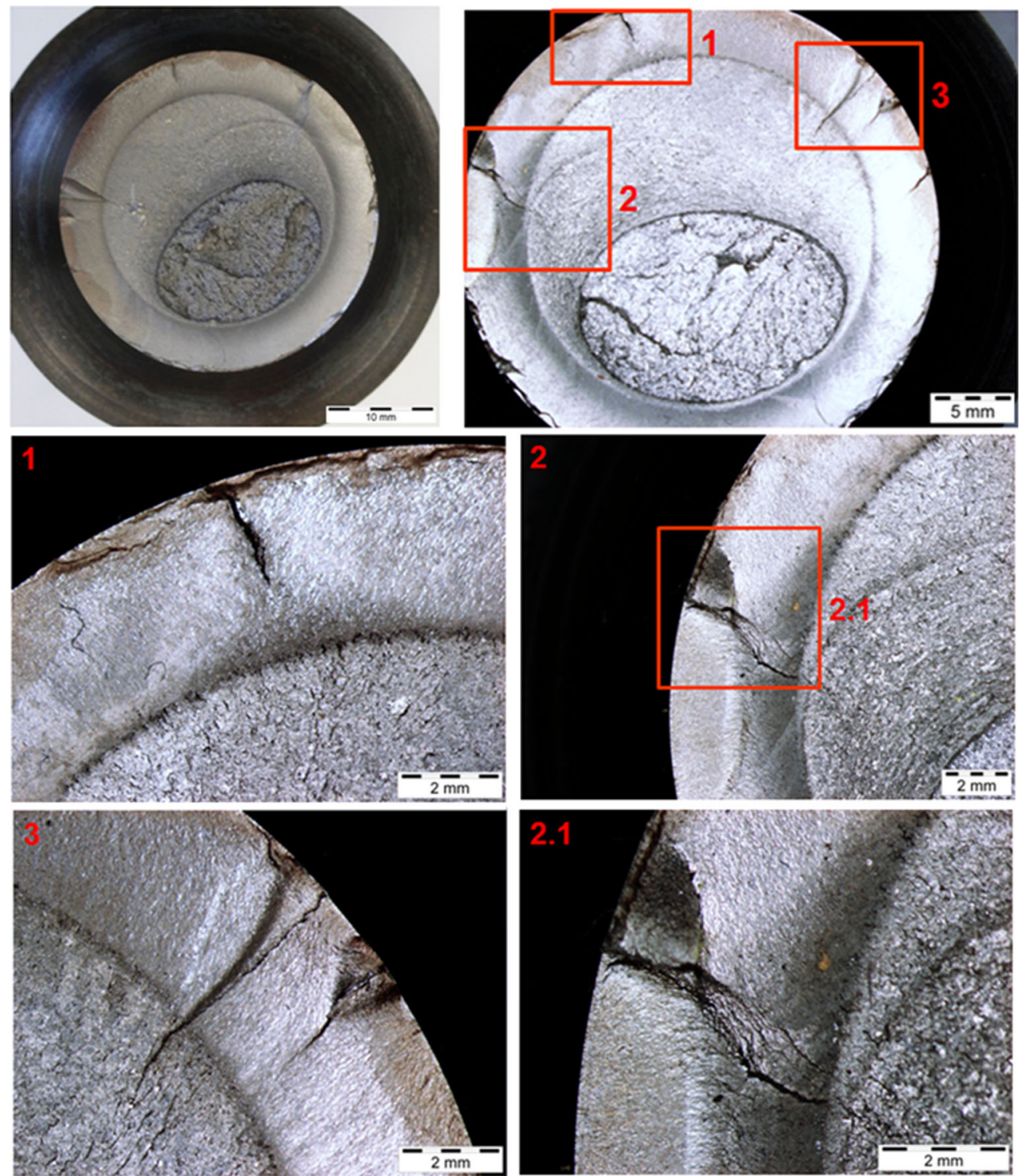

Fig. 15 Fracture surface of induction-hardened specimen tested at a normalized stress amplitude of $\sigma_{\mathrm{a}}=1.85$ 

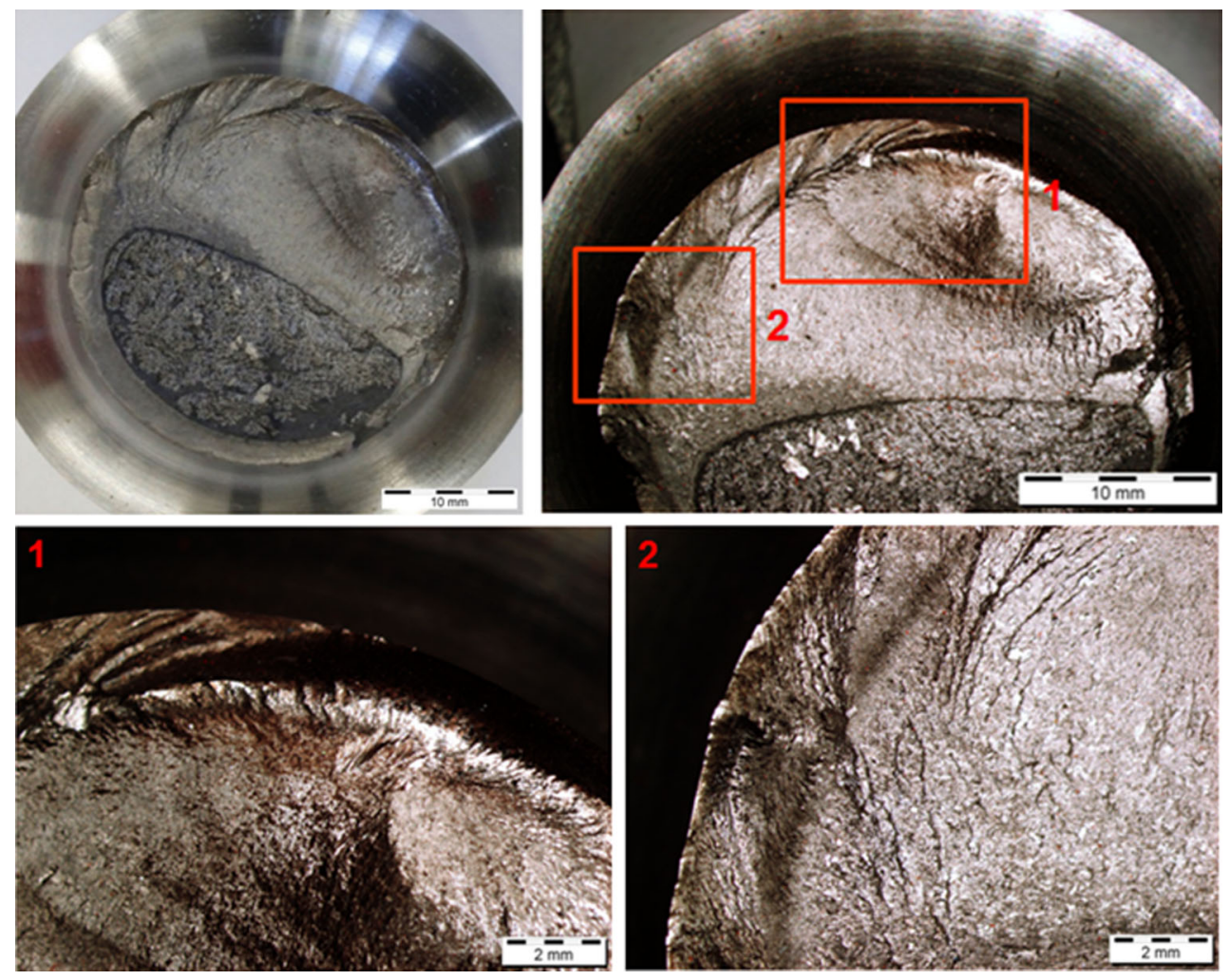

Fig. 16 Fracture surface of induction-hardened specimen tested at a normalized stress amplitude of $\sigma_{\mathrm{a}}=1.48$
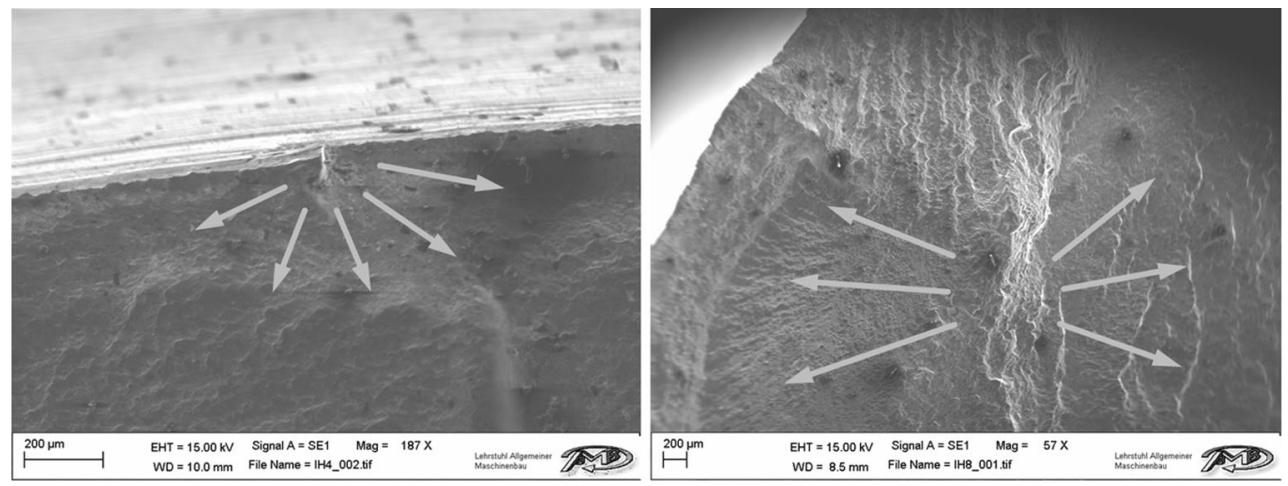

Fig. 17 SEM analysis of crack initiation for induction-hardened specimens tested at a normalized stress amplitude of $\sigma_{\mathrm{a}}=1.85$ (left) and $\sigma_{\mathrm{a}}=$ 1.48 (right)

surfaces of all tested samples does not indicate any defects or inclusions; hence, the failure mechanism can be mostly drawn to an interacting effect of the load-stress distribution and the local manufacturing process-based fatigue resistance in depth.

To clarify both different fracture modes, scanning electron microscopic (SEM) investigations of selected crack initiation points are additionally performed. Figure 17 (left) demonstrates the analysis for the crack shown in subfigure 1 of the induction-hardened specimen tested at $\sigma_{\mathrm{a}}=1.85$, compare to Fig. 15. It is highlighted that the fatigue crack originates at the surface of the hardened layer. Figure 17 (right) shows the results for the crack initiation shown in subfigure 2 of the induction-hardened specimen tested at $\sigma_{\mathrm{a}}=1.48$, compare to Fig. 16. Herein, crack origin can be detected at the transition of the hardened surface layer to the core material with further crack growth toward both directions.
Figure 18 depicts the fracture surface of an inductionhardened and additionally stroke-peened specimen tested at a comparably high load level of $\sigma_{\mathrm{a}}=2.11$ leading to a decreased number of about $3.6 \times 10^{4}$ load-cycles until burst fracture. Thereby, a similar behavior as presented for the inductionhardened condition is observed. Due to the comparably high local load stress at the surface of the notch, the local fatigue resistance is exceeded and crack initiation occurs at this area, which is again microscopically analyzed within this study.

Finally, a fracture surface of an induction-hardened and stroke-peened specimen, tested at a comparably low load level of $\sigma_{\mathrm{a}}=1.75$ leading to a number of about $4.0 \times 10^{5}$ loadcycles until burst fracture, is shown in Fig. 19. The exemplified analysis again reveals a crack initiation below the surface. As both post-treatment conditions exhibit a surface-hardened layer, generally the equal failure modes are detected for only 

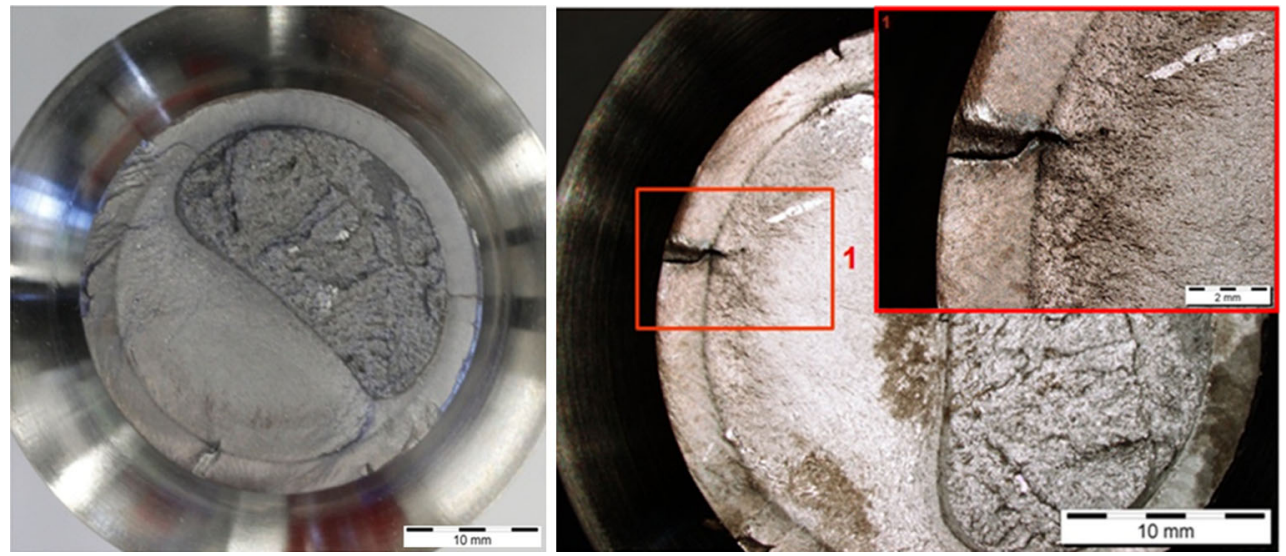

Fig. 18 Fracture surface of induction-hardened and stroke-peened specimen tested at a normalized stress amplitude of $\sigma_{\mathrm{a}}=2.11$
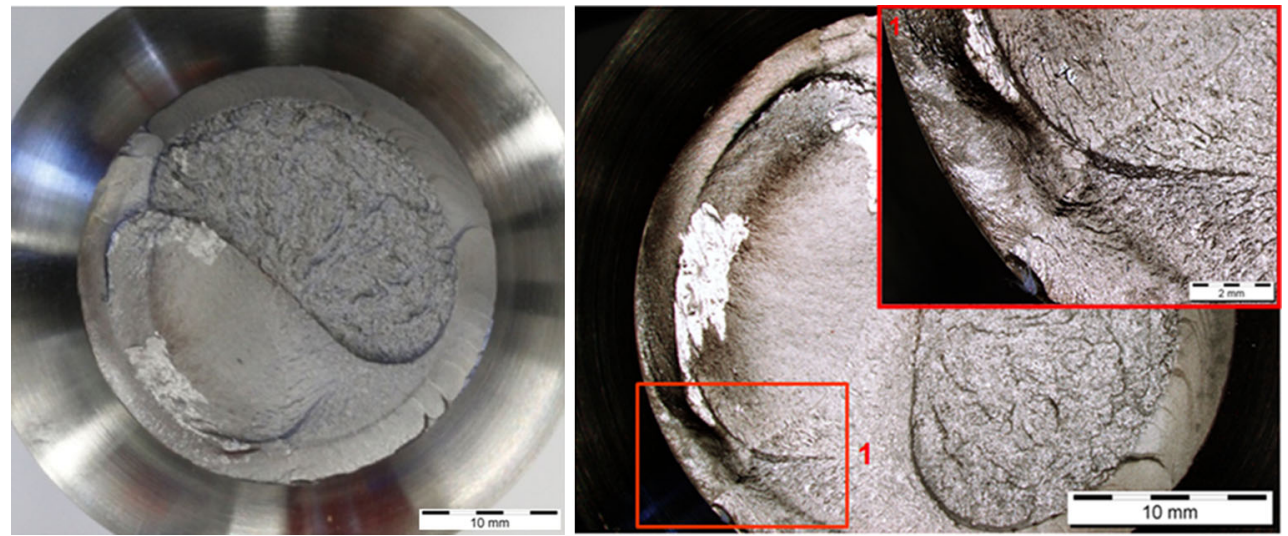

Fig. 19 Fracture surface of induction-hardened and stroke-peened specimen tested at a normalized stress amplitude of $\sigma_{\mathrm{a}}=1.75$
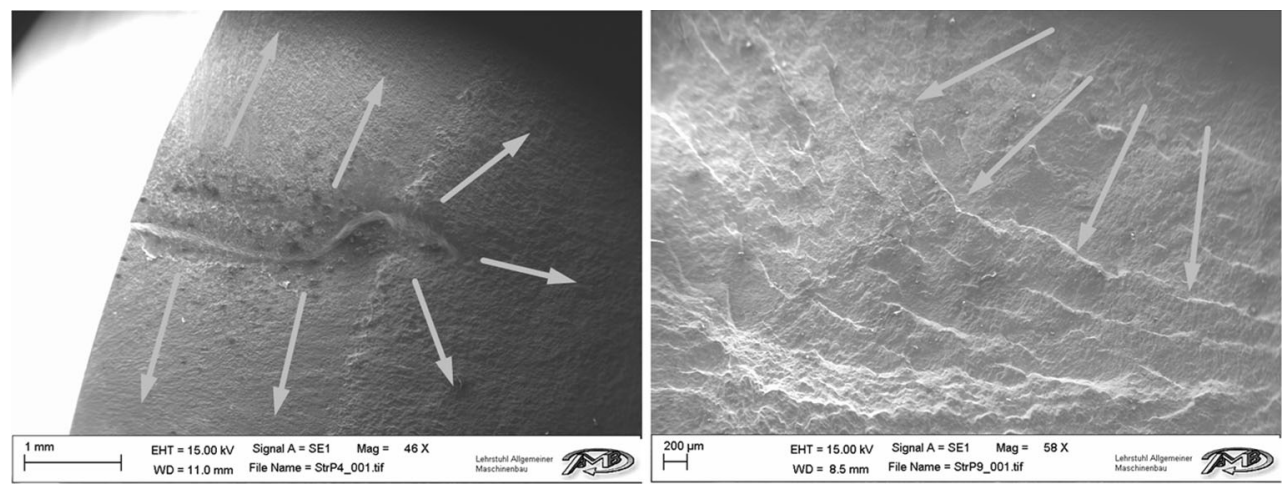

Fig. 20 SEM analysis of crack initiation for induction-hardened and stroke-peened specimens tested at $\sigma_{\mathrm{a}}=2.11$ (left) and $\sigma_{\mathrm{a}}=1.75$ (right)

induction hardening and after applying the superimposed stroke peening.

Again, a detailed SEM analysis of selected crack initiation points is performed. Figure 20 (left) reveals the analysis for the crack shown in subfigure 1 of the induction-hardened and stroke-peened specimen tested at $\sigma_{\mathrm{a}}=2.11$, compare to Fig. 18. It is shown that the fatigue crack initiation occurs at the surface of the hardened layer equivalent to the inductionhardened condition tested at a higher load level. Figure 20 (right) depicts the local fatigue crack behavior in subfigure 1 of the induction-hardened and stroke-peened spec- imen tested at $\sigma_{\mathrm{a}}=1.75$, compare to Fig. 19. Thereby, again the crack starts below the hardened layer and propagates toward the surface similar to the induction-hardened condition tested at a lower load level.

\section{Conclusions}

Although the influence of heat treatments (Ref 31) and mechanical surface processes (Ref 32) on the local material 
properties and fatigue strength of steel parts is comprehensively researched nowadays, investigations regarding the effect of a superimposed mechanical treatment on a heat-treated surface steel layer are comparatively rare in the literature. Therefore, this paper scientifically contributes to the fatigue strength of induction-hardened surface layers by stroke peening as superimposed mechanical post-treatment technique. Focus of application is laid on the highly stressed fillets of large gas engine $50 \mathrm{CrMo} 4$ steel crankshafts within this work. In addition to the fatigue tests, extensive measurements of the local material properties such as hardness and residual stresses states as well as a detailed fracture surface analysis based on light-optical and scanning electron microscopy is performed. Based on the presented results, the following conclusions can be drawn:

- Local microstructure as well as hardness profiles in depth of the investigated round specimen matches well to the measurements of the crankshaft for both post-treated conditions. A minor difference in Vicker's hardness up to a value of just $5 \%$ is observed.

- X-ray measured residual stress states in axial and tangential direction of the specimen shows sound agreement in the surface-near layer up to a depth of $50 \mu \mathrm{m}$ exhibiting a comparable small deviation up to $10 \%$ to the values of the crankshaft. However, slightly increased differences in the residual stress state occur up to a further depth of $1500 \mu \mathrm{m}$ due to size-effects between the small-scale round specimen and the large crankshaft in the course of the induction hardening and stroke-peening post-treatment process. Summarized, the manufactured specimens reveal comparable residual stress states as the crankshaft enabling a transferability of the acquired fatigue test results to the real application.

- Comprehensive x-ray measurements in case of the crankshaft facilitate the evaluation of an equivalent von Mises residual stress condition in depth, which shows a significant increase by over $70 \%$ of the average compressive residual stress state due to the superimposed stroke peening compared to the induction-hardened condition. This behavior majorly contributes to the fatigue strength enhancement by the additional mechanical post-treatment of the induction-hardened layer.

- Four-point bending fatigue tests reveal an increase of the nominal high-cycle fatigue strength by over $45 \%$ due to the induction hardening and by $75 \%$ due to the additional stroke peening, both values compared to the base material behavior. Hence, the superimposed mechanical post-treatment fundamentally enhances the high-cycle fatigue strength of induction-hardened surface layers by further $20 \%$.

- Fracture surface analysis of the investigated specimen types indicates that in case of the base material condition multiple crack initiation occurs at the surface around the circumference of the notched area. This failure mode is quite similar to both post-treated conditions, but only in case of comparable high load levels. In case of lower load levels, cracks initiate within the material beneath the surface-hardened layer, which can be generally explained by the concept of the local fatigue strength introduced in Ref 29.

Further work focuses on the investigation of the statistical size effect on the fatigue strength of surface-hardened components. Analytical and numerical procedures utilizing a highly stressed surface and volume approach are presented in Ref 33 for the base material condition, which act as basis for this prospective analysis. Thereby, an incorporation of common models like given in Ref 29 to include the influence of hardened surface layers is scheduled.

\section{Acknowledgments}

Open access funding provided by Montanuniversität Leoben.

\section{Open Access}

This article is distributed under the terms of the Creative Commons Attribution 4.0 International License (http://creativecommons.org/ licenses/by/4.0/), which permits unrestricted use, distribution, and reproduction in any medium, provided you give appropriate credit to the original author(s) and the source, provide a link to the Creative Commons license, and indicate if changes were made.

\section{References}

1. K. Payrhuber and C. Trapp, GE's New Jenbacher Gas Engines with 2Stage Turbocharging, 7. Internationale Energiewirtschaftstagung an der TU Wien, 2011 (Vienna, Austria) (in German)

2. W. Li, Q. Yan, and J. Xue, Analysis of a Crankshaft Fatigue Failure, Eng. Fail. Anal., 2015, 55, p 139-147

3. M. Fonte and M. de Freitas, Marine Main Engine Crankshaft Failure Analysis: A Case Study, Eng. Fail. Anal., 2009, 16, p 1940-1947

4. F. Jiménez Espadafor, J.A. Becerra Villanueva, and M. Torres García, Analysis of a Diesel Generator Crankshaft Failure, Eng. Fail. Anal., 2009, 16, p 2333-2341

5. J.A. Becerra Villanueva, F. Jiménez Espadafor, F. Cruz-Peragon, and M. Torres Garcia, A Methodology for Cracks Identification in Large Crankshafts, Mech. Syst. Signal Process., 2011, 25, p 3168-3185

6. J. Fröschl, F. Achatz, S. Rödling, and M. Decker, Innovative Component Test Concept for Crankshafts, Motortechn. Zeit., 2010, 71, $\mathrm{p} 44-48$

7. A. Fatemi and N. Shamsaei, Multiaxial Fatigue: An Overview and Some Approximation Models for Life Estimation, Int. J. Fatigue, 2011, 33, p 948-958

8. E. Macha and C.M. Sonsino, Energy Criteria of Multiaxial Fatigue Failure, Fatigue Fract. Eng. Mater. Struct., 1999, 22, p 1053-1070

9. T. Isogai and A.T. Yokobori, New Concept on Fatigue Crack Growth Characteristics under Combined Stress Conditions, Int. J. Fract., 2000, 102, p $47-52$

10. F.H. Montazersadgh and A. Fatemi, Dynamic Load and Stress Analysis of a Crankshaft, SAE Paper 2007-01-0258, 2007

11. F. Garcia, Crankshaft Fillet Hardening: Challenges and Prospects, Ind. Heat., 2014, August, p 47-48

12. H. Kristoffersen and P. Vomacka, Influence of Process Parameters for Induction Hardening on Residual Stresses, Mater. Des., 2001, 22, p 637-644

13. G. Çevik and R. Gürbüz, Evaluation of Fatigue Performance of a Fillet Rolled Diesel Engine Crankshaft, Eng. Fail. Anal., 2013, 27, p 250261

14. S. Ho, Y.L. Lee, H.T. Kang, and C.J. Wang, Optimization of a Crankshaft Rolling Process for Durability, Int. J. Fatigue, 2009, 31, p 799-808

15. F. Bleicher, C. Lechner, C. Habersohn, E. Kozeschnik, B. Adjassoho, and H. Kaminski, Mechanism of Surface Modification Using Machine Hammer Peening Technology, CIRP Ann. Manuf. Technol., 2012, 61, p 375-378

16. Z. Wang, C. Jiang, X. Gan, Y. Chen, and V. Ji, Influence of Shot Peening on the Fatigue Life of Laser Hardened 17-4PH Steel, Int. J. Fatigue, 2011, 33, p 549-556

17. D.L. McDowell, Basic Issues in the Mechanics of High Cycle Metal Fatigue, Intern. J. Fract., 1996, 80, p 103-145

18. M. Leitner, Z. Tuncali, W. Chen, R. Steiner, and F. Grün, Multiaxial fatigue assessment of crankshafts by local stress and critical plane 
approach, in Proceedings of the International Conference on Multiaxial Fatigue \& Fracture, 2016 (Seville, Spain)

19. M. Leitner, Z. Tuncali, R. Steiner, and F. Grün, Multiaxial Fatigue Strength Assessment of Electroslag Remelted 50CrMo4 Steel Crankshafts, Int. J. Fatigue, 2017, 100, p 159-175

20. Steels for Quenching and tempering_Part 3: Technical Delivery Conditions for Alloy Steels, DIN EN Standard 10083-3, 2007

21. M. Leitner, R. Aigner, and D. Dobberke, Local Fatigue Strength Assessment of Induction Hardened Components Based on Numerical Manufacturing Process Simulation, Proc. Eng., 2018, 213, p 644 650

22. A.M. Abrao, B. Denkena, B. Breidenstein, and T. Mörke, Surface and Subsurface Alterations Induced by Deep Rolling of Hardened AISI, 1060 Steel, Prod. Eng., 2014, 8, p 551-558

23. N.S. Rossini, M. Dassisti, K.Y. Benyounis, and A.G. Olabi, Methods of Measuring Residual Stresses in Components, Mater. Des., 2012, 35, p $572-588$

24. Standard Practice for Statistical Analysis of Linear or Linearized Stress-Life (S-N) and Strain-Life (e-N) Fatigue Data, E 739, ASTM, 1998

25. D. Dengel, Arc Sine $\sqrt{ }$ P-Transformation-An Effective Tool for Graphical and Numerical Evaluation of Planned Wohler-Experiments, J. Mater. Technol., 1975, 8, p 253-261
26. S.A. McKelvey, Y.L. Lee, and M.E. Barkey, Stress-Based Uniaxial Fatigue Analysis Using Methods Described in FKM-Guideline, J. Fail. Anal. Prev., 2012, 12, p 445-484

27. R.O. Ritchie, Mechanisms of Fatigue-Crack Propagation in Ductile and Brittle Solids, Intern. J. Fract., 1999, 100, p 55-83

28. A. Tjernberg, Fatigue Live for Induction Hardened Shafts with Subsurface Crack Initiation, Eng. Fail. Anal., 2002, 9, p 45-61

29. K.H. Kloos and E. Velten, Berechnung der Dauerschwingfestigkeit von plasmanitrierten bauteilähnlichen Proben unter Berücksichtigung des Härte- und Eigenspannungsverlaufs, Konstruktion, 1984, 36, p 181-188 (in German)

30. B. Winderlich, The Local Fatigue Strength Concept and Its Application to Martensitic Surface Layers, Especially Laser Hardened Layers, Mat.-wiss. u. Werkstofftech., 1990, 21, p 378-389 (in German)

31. ASM Handbook, Volume 4A: Steel Heat Treating Fundamentals and Processes, ASM International, Materials Park, OH, 2013. https://www. asminternational.org/search/-/journal content/56/10192/05344G/PUB LICATION

32. ASM Handbook Volume 5: Surface Engineering, ASM International, Materials Park, OH, 1994. https://www.asminternational.org/news/-/ journal content/56/10192/06125G/PUBLICATION

33. M. Leitner, M. Vormwald, and H. Remes, Statistical Size Effect on Multiaxial Fatigue Strength of Notched Steel Components, Int. J. Fatigue, 2017, 104, p 322-333 